\title{
Treatment, outcomes, and demographics in sinonasal sarcoma: a systematic review of the literature
}

\author{
Mitchell R. Gore(D)
}

\begin{abstract}
Background: Sarcomas comprise a diverse group of soft tissue mesenchymal malignancies. The sinuses and nasal region are a relatively rare site of sarcomas.

Methods: Retrospective review of the literature on sinonasal sarcomas from 1987-2017. Data were analyzed for demographics, treatment type, stage, and histopathologic type. Kaplan-Meier analysis was used to assess and compare survival.

Results: A total of 198 cases of sinonasal sarcoma were identified and analyzed. The median age at diagnosis was 39 years. Overall 5-, 10-, and 20-year survival was 61.3\%, 58.9\%, and 49.1\%, respectively, and disease-free 5-, 10-, and 20 -year survival was $53.2 \%, 49.1 \%$, and $38.3 \%$, respectively. Lymph node metastasis was present at diagnosis in 3.0\% of cases, and distant metastasis was present in $3.5 \%$ of cases. On univariate analysis T stage, overall stage, treatment type, histopathologic subtype, and presence of distant metastasis significantly affected survival. On multivariate analysis overall stage alone significantly predicted overall survival. Open vs. endoscopic surgery, total radiation dose, and presence of neck metastasis did not significantly affect survival. Combined modality treatment was associated with higher survival rates than single modality therapy.

Conclusions: Sinonasal sarcoma is a relatively rare malignancy. Lower T and overall stage, lack of distant metastasis, and multimodality therapy were associated with improved survival. Certain histopathologic subtypes were associated with poorer survival.
\end{abstract}

Keywords: Sinonasal sarcoma, Endoscopic, Survival, Kaplan-Meier, Sinonasal cancer

\section{Background}

Sarcomas of the head and neck region account for less than $10 \%$ of soft tissue sarcomas, and comprise less than $1 \%$ of head and neck malignancies $[1,2]$. Sarcomas arise from mesenchymal tissue, and more than 50 histopathological subtypes of sarcoma have been reported. Approximately $80 \%$ of sarcomas arise from soft tissue, with the remaining originating from bone or cartilage. Head and neck sarcomas typically occur more frequently in men. While several recent studies have reported extensive patient data on specific histologic subtypes of sinonasal sarcoma [3-9], no recent study has examined the aggregate survival outcomes of the various subtypes of sarcoma found in the sinonasal cavity. Given the diverse

Correspondence: mgoremdphd@gmail.com

Syracuse, USA histopathological subgroups comprising head and neck sarcomas, etiological factors have not been clearly elucidated in all subtypes. Some sarcoma subtypes are associated with known genetic factors, such as the translocation involving chromosomes $\mathrm{X}$ and 18 specific to synovial sarcoma, or the common $t(11 ; 22)(\mathrm{q} 24 ; \mathrm{q} 12)$ translocation present in the majority of Ewing's sarcoma cases [7]. Sarcomas may be associated with diseases such as p53 mutations, basal cell nevus syndrome, Werner's syndrome, tuberous sclerosis, neurofibromatosis, Gardner's syndrome, and Li-Fraumeni syndrome. Previous irradiation for prior cancers or Epstein-Barr virus infection may also be associated with an increased risk of sarcoma. Most sarcomas are sporadic, not hereditary, in etiology [1-9]. 
Sarcomas of the sinonasal region may present a diagnostic challenge, as their location in the sinuses or nasal cavity may lead to presenting symptoms such as epistaxis, nasal congestion, or sinus pain and pressure that may be attributed to more benign causes such as chronic sinusitis, sinonasal polyposis, or allergic rhinitis. The less common sinonasal sarcoma subtypes may present a diagnostic challenge as their histopathological characteristics may overlap, especially with variations in tumor grade or with dedifferentiation. Additionally, the ideal treatment modality may present a therapeutic challenge, as the response to radiation and/or chemotherapy may vary according to the sarcoma subtype. Many patients are treated with multimodality therapy for sarcomas such as Ewing's sarcoma, with surgery and/or radiation for local control, and chemotherapy for systemic treatment. Long-term surveillance of sinonasal sarcoma is necessary to monitor for and to detect recurrences and to allow salvage treatment if recurrence is detected.

Given the relative lack of literature on the aggregate survival outcomes and treatment in the diverse (and less common) histopathological types of sinonasal sarcoma, this study aimed to report the demographics, treatment modalities, and survival outcomes of patients treated for sinonasal sarcoma from studies published from 19872017. The study examined the correlation between survival outcomes and the AJCC (American Joint Committee on Cancer) sarcoma stage, tumor grade, presence of neck or distant metastasis, tumor type, treatment type, and endoscopic, endoscopic-assisted, or open surgery.

\section{Methods}

Systematic review and meta-analysis

A Pubmed literature search was conducted using the search terms "sinus + nasal + sarcoma". This literature review and meta-analysis was carried out and reported using the Preferred Reporting Items for Systematic Reviews and Meta-Analysis (PRISMA) Additional file 1 guidelines for the reporting of observational studies [10]. Figure 1 illustrates the PRISMA flow diagram for study selection. For the period 1987-2017 481 total papers were identified. After excluding duplicate studies, review articles, and studies without analyzable individual patient data, a total of 174 studies reporting 198 total patients were identified [11-184]. Case reports, case series, and cohort studies containing individual analyzable patient data on patients of any age with a pathologic diagnosis of sinonasal sarcoma were included in the meta-analysis of survival outcomes. The outcomes were overall survival and disease-free survival.

\section{Statistical analysis}

Statistical analyses were performed with XLSTAT Biomed (Addinsoft, New York, NY, USA/Paris, France). Overall patient demographics, tumor histopathology, treatment factors, and outcomes were compiled via

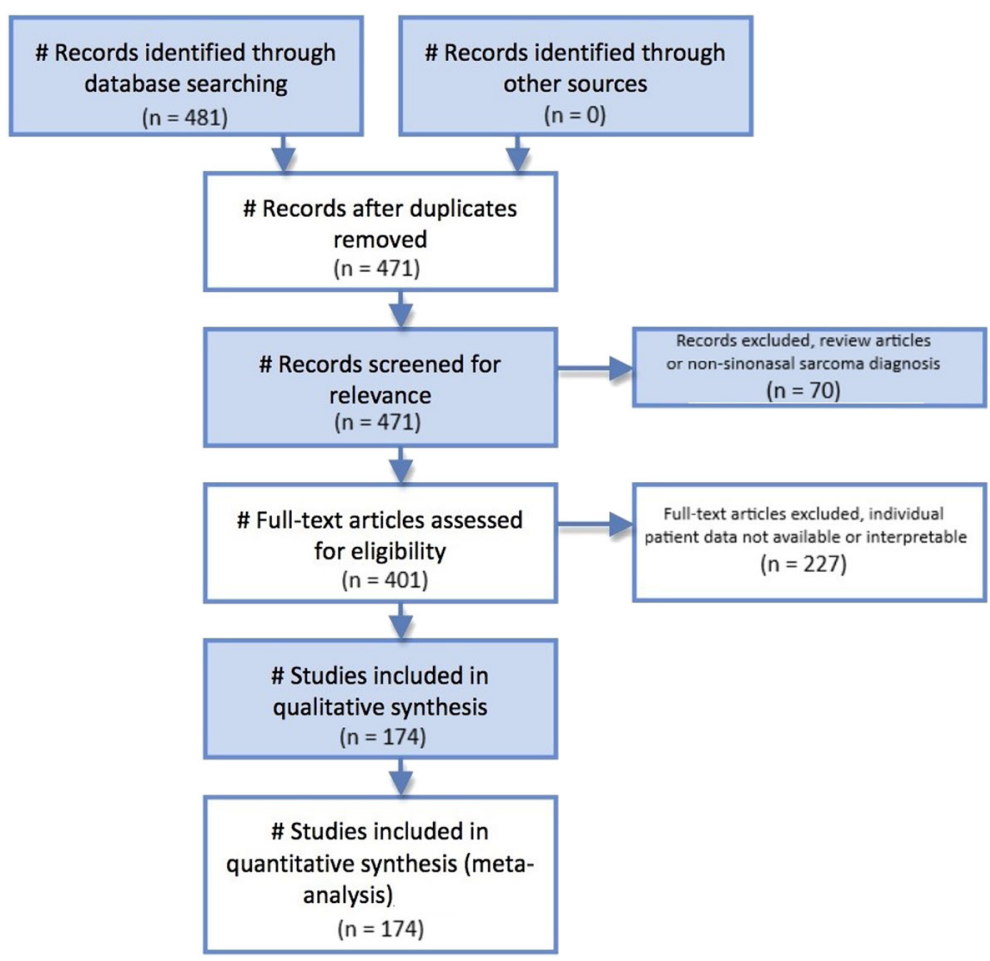

Fig. 1 PRISMA diagram illustrating the methods for study selection 
standard summary statistical methods. Tumors were staged according to the American Joint Committee on Cancer (AJCC) sarcoma staging system. Kaplan-Meier actuarial survival analysis and the log-rank test of statistical significance were performed to determine the univariate association between overall and disease-free survival and sarcoma $\mathrm{T}$ stage, overall sarcoma stage, treatment modality, neck metastasis, distant metastasis, tumor grade, total radiation dose $<$ or $>/=50$ Gray, and open, endoscopic assisted open, or endoscopic surgery. Linear regression was used to perform multivariate analysis. P values less than 0.05 were considered statistically significant.

\section{Results}

\section{Demographics}

One hundred ninety-eight patients were identified. Of patients for whom data on sex was available, 69.6\% (128) were male, and $30.4 \%$ (56) were female (2.3:1 ratio). The average patient age was 38.4 years, the mean age was 39 years. Table 1 lists the sex, T, N, M, and stage demographics for the cohort. Table 2 lists the tumor type demographics. Table 3 lists the treatment types for the patients in the cohort. The histopathological diagnosis was alveolar soft part sarcoma in one patient $(0.5 \%)$, angiosarcoma in four patients $(2.0 \%)$, carcinosarcoma in two patients $(1.0 \%)$, chondrosarcoma in sixteen patients (8.1\%), Ewing's sarcoma in fifty-six patients (28.3\%), fibrosarcoma in five patients (2.5\%), granulocytic sarcoma in five patients $(2.5 \%)$, interdigitating dendritic cell sarcoma in one patient $(0.5 \%)$, leiomyosarcoma in twelve patients $(6.1 \%)$, liposarcoma in two patients (1.0\%), low grade sinonasal sarcoma with neural and myogenic features in two patients (1.0\%), myofibroblastic sarcoma in two patients (1.0\%), myxofibrosarcoma in three patients (1.5\%), neurofibrosarcoma in one patient $(0.5 \%)$, neurosarcoma in one patient $(0.5 \%)$, osteosarcoma in eleven

Table 1 Sex, T, N, M, and overall stage demographics for the sinonasal sarcoma cohort

\begin{tabular}{lll}
\hline Characteristic & $\mathrm{n}$ & $\%$ \\
\hline Male & 128 & $69.6 \%$ \\
Female & 56 & $30.4 \%$ \\
M+ & 7 & $3.5 \%$ \\
M0 & 191 & $96.5 \%$ \\
$\mathrm{~N}+$ & 6 & $3.0 \%$ \\
NO & 192 & $97.0 \%$ \\
T1 & 113 & $57.1 \%$ \\
T2 & 85 & $42.9 \%$ \\
Stage I + Stage II & 137 & $69.2 \%$ \\
Stage III & 56 & $28.3 \%$ \\
Stage IV & 5 & $2.5 \%$ \\
\hline
\end{tabular}

Table 2 Tumor type demographics for the sinonasal sarcoma cohort

\begin{tabular}{|c|c|c|}
\hline Tumor Type & $\mathrm{n}$ & $\%$ \\
\hline Alveolar soft part sarcoma & 1 & $0.5 \%$ \\
\hline Angiosarcoma & 4 & $2.0 \%$ \\
\hline Carcinosarcoma & 2 & $1.0 \%$ \\
\hline Chondrosarcoma & 16 & $8.1 \%$ \\
\hline Ewing's sarcoma & 56 & $28.3 \%$ \\
\hline Fibrosarcoma & 5 & $2.5 \%$ \\
\hline Granulocytic sarcoma & 5 & $2.5 \%$ \\
\hline Interdigitating dendritic cell sarcoma & 1 & $0.5 \%$ \\
\hline Leiomyosarcoma & 12 & $6.1 \%$ \\
\hline Liposarcoma & 2 & $1.0 \%$ \\
\hline $\begin{array}{l}\text { Low grade sinonasal sarcoma with neural and } \\
\text { myogenic features }\end{array}$ & 2 & $1.0 \%$ \\
\hline Myofibroblastic sarcoma & 2 & $1.0 \%$ \\
\hline Myxofibrosarcoma & 3 & $1.5 \%$ \\
\hline Neurofibrosarcoma & 1 & $0.5 \%$ \\
\hline Neurosarcoma & 1 & $0.5 \%$ \\
\hline Osteosarcoma & 11 & $5.6 \%$ \\
\hline Peripheral neuroectodermal tumor (PNET) & 14 & $7.1 \%$ \\
\hline Rhabdomyosarcoma & 14 & $7.1 \%$ \\
\hline Sarcomatoid sarcoma & 1 & $0.5 \%$ \\
\hline Synovial sarcoma & 2 & $1.0 \%$ \\
\hline Teratocarcinosarcoma & 14 & $7.1 \%$ \\
\hline Teratosarcoma & 1 & $0.5 \%$ \\
\hline $\begin{array}{l}\text { Triton tumor (malignant peripheral nerve sheath } \\
\text { tumor with rhabdomyosarcomatous differentiation) }\end{array}$ & 2 & $1.0 \%$ \\
\hline $\begin{array}{l}\text { Undifferentiated pleomorphic sarcoma/malignant } \\
\text { fibrous histiocytoma (UPS/MFH) }\end{array}$ & 25 & $12.6 \%$ \\
\hline
\end{tabular}

patients (5.6\%), peripheral neuroectodermal tumor (PNET) in fourteen patients (7.1\%), rhabdomyosarcoma in fourteen patients (7.1\%), sarcomatoid sarcoma in one patient $(0.5 \%)$, synovial sarcoma in two patients $(1.0 \%)$, teratocarcinosarcoma in fourteen patients $(7.1 \%)$, teratosarcoma

Table 3 Treatment type demographics for the sinonasal sarcoma cohort

\begin{tabular}{lll}
\hline Treatment & $\mathrm{n}$ & $\%$ \\
\hline Surgery + radiation + chemotherapy & 37 & $18.7 \%$ \\
Surgery + radiation & 44 & $22.2 \%$ \\
Surgery + chemotherapy & 17 & $8.6 \%$ \\
Surgery alone & 45 & $22.7 \%$ \\
Radiation + chemotherapy & 33 & $16.7 \%$ \\
Radiation alone & 3 & $1.5 \%$ \\
Chemotherapy alone & 10 & $5.1 \%$ \\
Palliative treatment & 2 & $1.0 \%$ \\
No treatment & 1 & $0.5 \%$ \\
\hline
\end{tabular}


in one patient $(0.5 \%)$, Triton tumor (malignant peripheral nerve sheath tumor with rhabdomyosarcomatous differentiation) in two patients (1.0\%), and undifferentiated pleomorphic sarcoma/malignant fibrous histiocytoma (UPS/ MFH) in 25 patients (12.6\%).

\section{Survival analysis}

The site of tumor involvement was the nasal cavity in 110 patients, maxillary sinus in 115 patients, ethmoid sinus in 55 patients, sphenoid sinus in 20 patients, frontal sinus in 20 patients, the orbit in 54 patients, the dura in 7 patients, brain in 4 patients, the cribriform plate in 7 patients, the cavernous sinus in 3 patients, and the sella turcica in 5 patients (numbers $>198$ due to individual patients having more than one site of tumor involvement). Seven patients (3.5\%) had distant metastasis $(\mathrm{M}+)$ at the time of diagnosis, and six patients $(3.0 \%)$ had cervical metastasis $(\mathrm{N}+)$ at the time of diagnosis. Overall survival (OS) at 60 months, 120 months, and 240 months was $61.3 \%, 58.9 \%$, and $49.1 \%$, respectively (Fig. 2), with a mean overall actuarial survival of 130.6 months. Disease-free survival (DFS) at 60 months, 120 months, and 240 months was $53.2 \%, 49.1 \%$, and $38.3 \%$, respectively (Fig. 3), with a mean disease-free actuarial survival of 111.2 months. Survival was improved for patients who did not experience disease recurrence, and the relative survival in patients who did not experience a recurrence $(n=122)$ vs. patients who experienced a recurrence $(n=76)$ was $2.5: 1(p=0.0001)$.

Figure 4a shows the Kaplan-Meier actuarial overall survival by stage, while Fig. $4 \mathrm{~b}$ shows the Kaplan-Meier actuarial disease-free survival by stage. Overall survival at 60 months was $65.5 \%$ for stage I + stage II $(n=137)$, $56.8 \%$ for stage III $(n=56)$, and $0 \%$ for stage IV $(n=5)$, $p=0.001$. Disease-free survival at 60 months was $60.8 \%$



Fig. 2 Kaplan-Meier overall survival for all patients

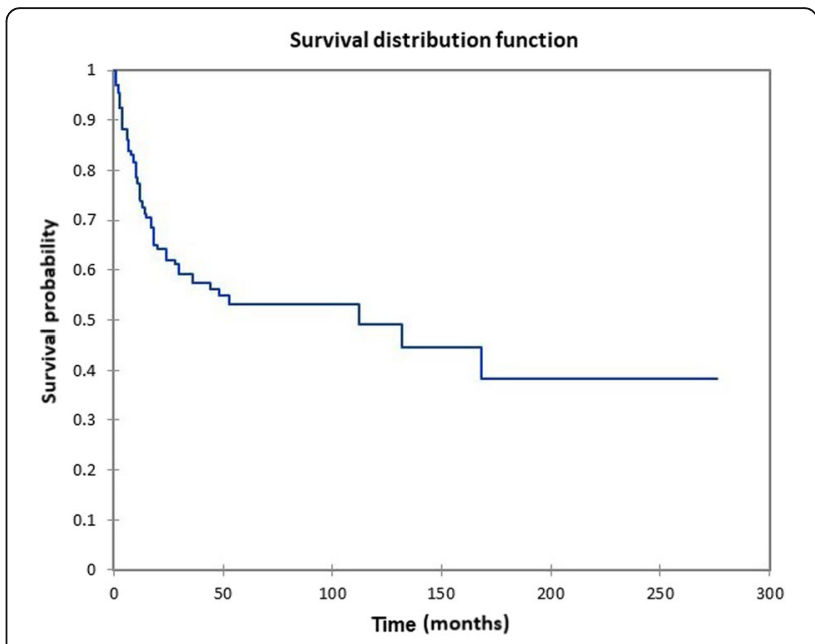

Fig. 3 Kaplan Meier disease-free survival for all patients

for stage I + stage II $(n=137), 34.6 \%$ for stage III $(n=$ $56)$, and $0 \%$ for stage IV $(n=5), p<0.0001$.

Figure 5a shows the Kaplan-Meier actuarial overall survival by tumor $(\mathrm{T})$ stage, while Fig. $5 \mathrm{~b}$ shows the Kaplan-Meier actuarial disease-free survival by tumor (T). Overall survival at 60 months was $61.7 \%$ for T1 $(n=$ $113)$, and $65.8 \%$ for T2 $(n=85), p=0.2$. Disease-free survival at 60 months was $59.6 \%$ for $\mathrm{T} 1(n=113)$, and $40.8 \%$ for T2 $(n=85), p=0.04$.

Figure 6a shows the Kaplan-Meier actuarial overall survival by tumor grade (G), while Fig. 6b shows the Kaplan-Meier actuarial disease-free survival by tumor grade. Mean overall survival for grade $1(n=5)$ was 12 months, grade 2 was 6 months $(n=1)$, and grade 3 was 3 months $(n=1), p=0.05$, while mean disease-free survival for grade 1 was 11.0 months $(n=5)$, grade 2 was 6 months $(n=1)$, and grade 3 was 3 months $(n=1), p=$ 0.05 . Figure 7a shows the Kaplan-Meier actuarial overall survival by radiation dose, while Fig. $7 \mathrm{~b}$ shows the Kaplan-Meier actuarial disease-free survival by radiation dose. Overall survival at 60 months was $91.7 \%$ for $<50$ Gray $(n=12)$, and $82.9 \%$ for $>/=50$ Gray $(n$ $=42, p=0.2$ ). Disease-free survival at 60 months was $91.7 \%$ for $<50$ Gray $(n=12)$, and $68.9 \%$ for $>/=50$ Gray $(n=42, p=0.1)$.

Figure 8a shows the Kaplan-Meier actuarial overall survival for M0 (no distant metastasis) vs. M1 (distant metastasis present) patients, while Fig. $8 \mathrm{~b}$ shows the Kaplan-Meier actuarial disease-free survival for M0 vs. M1 patients. Overall survival at 60 months was $62.7 \%$ for M0 patients $(n=191)$, and $0 \%$ for M1 patients $(n=$ $7), p<0.0001$. Disease-free survival at 60 months was $54.6 \%$ for M0 patients $(n=191)$, and $0 \%$ for M1 patients $(n=7), p<0.0001$. Figure 9a shows the Kaplan-Meier actuarial overall survival for N0 (no neck metastasis) vs. $\mathrm{N}+$ (neck metastasis present) patients, while Fig. 9b 

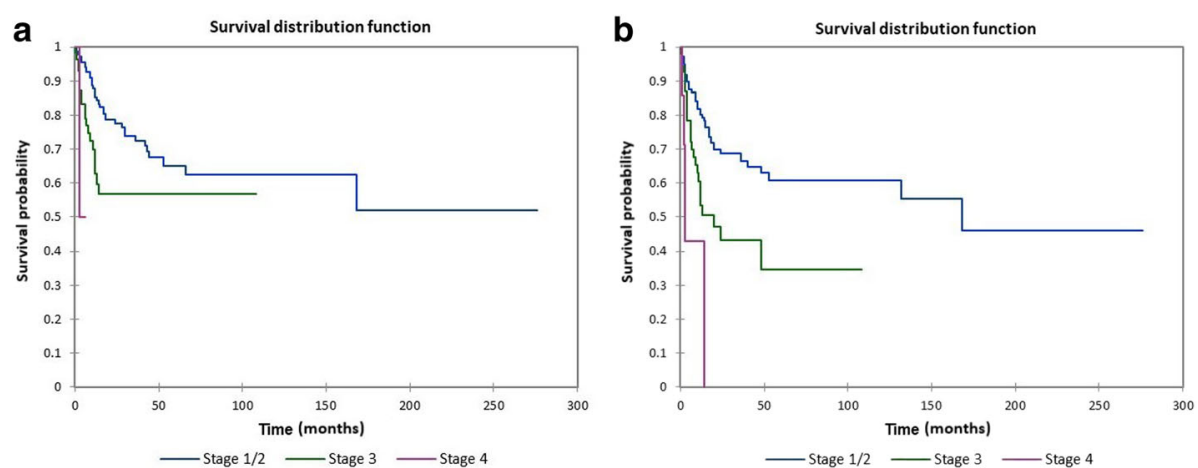

Fig. 4 a Kaplan-Meier overall survival by stage. b Kaplan-Meier disease-free survival by stage

shows the Kaplan-Meier actuarial disease-free survival for N0 vs. N+ patients. Overall survival at 60 months was $61.0 \%$ for N0 patients $(n=192)$, and NA (not available) for $\mathrm{N}+$ patients $(n=6), p=0.3$. Disease-free survival at 60 months was $53.8 \%$ for N0 patients $(n=192)$, and NA for $\mathrm{N}+$ patients $(n=6), p=0.2$.

Figure 10a shows the Kaplan-Meier actuarial overall survival by treatment modality, while Fig. 10b shows the Kaplan-Meier actuarial disease-free survival by treatment modality. Overall survival at 60 months was $90.9 \%$ for surgery + radiation + chemotherapy $(n=37), 79.9 \%$ for surgery + radiation $(n=44), 71.3 \%$ for surgery + chemotherapy $(n=17), 40.9 \%$ for surgery alone $(n=45)$, $66 \%$ for radiation + chemotherapy $(n=33)$, NA for radiation alone $(n=3)$ and chemotherapy alone $(n=10)$, and $0 \%$ for palliative treatment $(n=2)$ and no treatment $(n=1), p<0.0001$. Disease-free survival at 60 months was $80.8 \%$ for surgery + radiation + chemotherapy $(n=$ $37), 67.9 \%$ for surgery + radiation $(n=44), 60.7 \%$ for surgery + chemotherapy $(n=17), 40.9 \%$ for surgery alone $(n=45), 57.2 \%$ for radiation + chemotherapy $(n=$ $33)$, NA for radiation alone $(n=3)$ and chemotherapy alone $(n=10)$, and $0 \%$ for palliative treatment $(n=2)$ and no treatment $(n=1), p<0.0001$.

Figure 11a shows the Kaplan-Meier actuarial overall survival by histopathological tumor type, while Fig. 11b shows the Kaplan-Meier actuarial disease-free survival by histopathological tumor type. Overall survival at 60 months was greatest for chondrosarcoma $(92.3 \%, n=$ 16), Ewing's sarcoma $(81.8 \%, n=56)$, osteosarcoma (63.6\%, $n=11)$, PNET $(76.6 \%, n=14)$, teratocarcinosarcoma $(68.6 \%, n=14)$, myofibroblastic sarcoma $(100 \%, n$ $=2)$, Triton tumor $(100 \%, n=2)$, leiomyosarcoma (61.9\%, $n=12)$, and worse for carcinosarcoma $(0 \%, n=$ 2), neurosarcoma $(0 \%, n=1)$, rhabdomyosarcoma $(47.2 \%, n=14)$, sarcomatoid sarcoma $(0 \%, n=1)$, teratosarcoma $(0 \%, n=1)$, PUS/MFH $(24 \%, n=25)$, and NA for angiosarcoma $(n=4)$, fibrosarcoma $(n=5)$, granulocytic sarcoma $(n=5)$, interdigitating dendritic cell sarcoma $(n=1)$, liposarcoma $(n=2)$, myxofibrosarcoma $(n=$ $3)$, neurofibrosarcoma $(n=1)$, and synovial sarcoma $(n=$ $2)$, and alveolar soft part sarcoma $(n=1), p<0.0001$. Disease-free survival at 60 months was greatest for chondrosarcoma (86\%, $n=16)$, Ewing's sarcoma $(75 \%, n=56)$, osteosarcoma $(54.5 \%, n=11)$, PNET $(68.1 \%, n=14)$, teratocarcinosarcoma ( $47 \%, n=14)$, myofibroblastic sarcoma $(50 \%, n=2)$, Triton tumor $(50 \%, n=2)$, and worse for carcinosarcoma $(0 \%, n=2)$, neurosarcoma $(0 \%, n=1)$, sarcomatoid sarcoma $(0 \%, n=1)$, teratosarcoma $(0 \%, n=1)$, PUS/MFH $(20 \%, n=25)$, and NA for angiosarcoma $(n=$ 4), fibrosarcoma $(n=5)$, granulocytic sarcoma $(n=5)$, interdigitating dendritic cell sarcoma $(n=1)$, liposarcoma
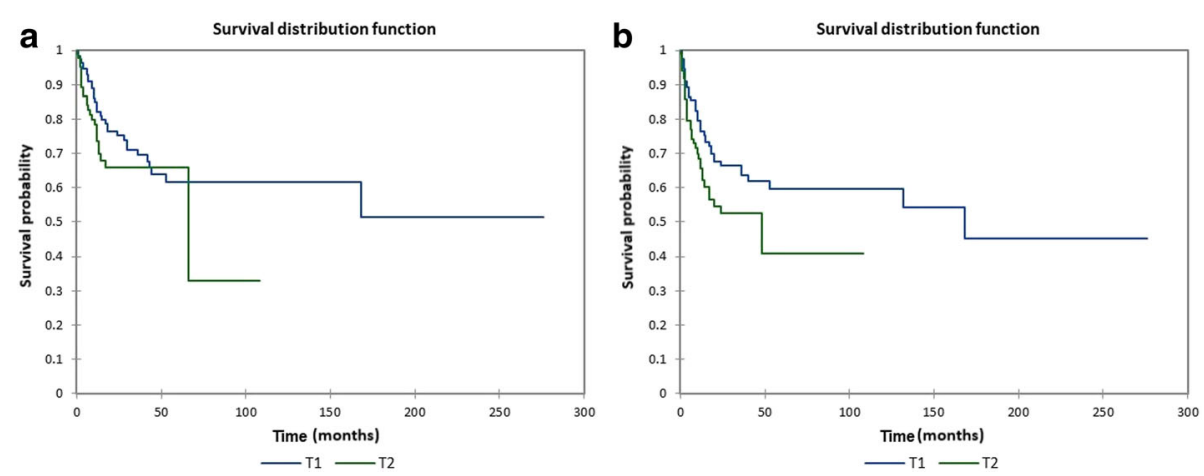

Fig. 5 a Kaplan-Meier overall survival by tumor (T) stage. b Kaplan-Meier disease-free survival by tumor (T) stage 

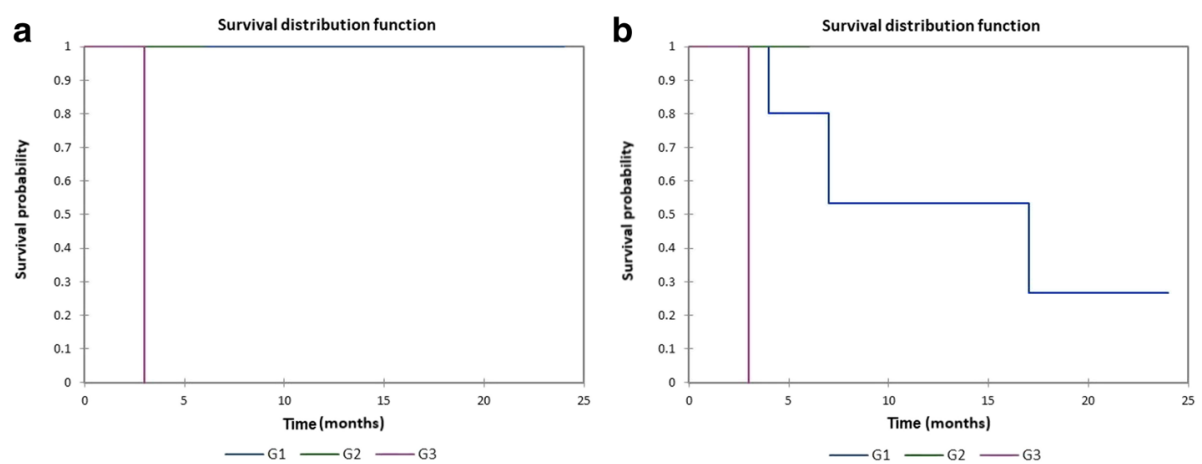

Fig. 6 a Kaplan-Meier overall survival by tumor grade (G). b Kaplan-Meier disease-free survival by tumor grade (G)

$(n=2)$, myxofibrosarcoma $(n=3)$, neurofibrosarcoma $(n$ $=1)$, and synovial sarcoma $(n=2)$, leiomyosarcoma $(n=$ 12), rhabdomyosarcoma $(n=14)$, and alveolar soft part sarcoma $(n=1), p<0.0001$.

Figure 12a shows the Kaplan-Meier actuarial overall survival for endoscopic assisted open surgery (endoscopic + open) vs. open surgery vs. endoscopic surgery, while Fig. 12b shows the Kaplan-Meier actuarial diseasefree survival for endoscopic assisted open surgery (endoscopic + open) vs. open surgery vs. endoscopic surgery. Overall survival at 60 months was $100 \%$ for endoscopic assisted open surgery $(n=3), 77.8 \%$ for open surgery $(n=$ $57)$, and $68.5 \%$ for endoscopic surgery $(n=24), p=0.8$. Disease-free survival at 60 months was $100.0 \%$ for endoscopic assisted open surgery $(n=3), 72.0 \%$ for open surgery $(n=57)$, and $55 \%$ for endoscopic surgery $(n=24), p=0.4$.

Linear regression was utilized to conduct a multivariate analysis for overall and disease-free survival. On multivariate analysis overall stage alone was a significant predictor of overall survival $(p<0.0001)$. On multivariate analysis overall stage was not a significant predictor of disease-free survival $(p=0.1)$.

\section{Discussion}

Sarcomas of the head and neck are relatively uncommon, accounting for approximately $10 \%$ or less of head and neck tumors. The sinonasal region is even more uncommon, with rhabdomyosarcoma of the sinonasal region occurring in approximately $0.034 / 100,000$ persons. In the present study the mean age was 39 , with a male to female ratio of $2.3: 1$. In their study of head and neck sarcomas in patients treated at St. Thomas' NHS (National Health Service) Foundation Trust from 1996-2012 Stavrakas et al. [2] noted a mean age of 62 and a male to female ratio of approximately $2: 1$.

The present study showed a significant relationship on univariate analysis between actuarial survival and tumor histopathological type (OS and DFS), presence of distant metastasis (OS and DFS), treatment type (OS and DFS), and $\mathrm{T}$ stage (DFS). Tumor grade approached significance despite low numbers of patients with specific tumor grade reported (OS and DFS). Open vs. endoscopic assisted vs. endoscopic surgery, radiation dose $<$ or $>/=$ 50 Gray, and presence of neck metastasis was not significantly associated with overall or disease-free survival on univariate analysis. The overall and disease-free survival at 60 months for all patients was $61.3 \%$ and $53.2 \%$, respectively. This is higher than the overall (25.6\%) and disease-free (25.6\%) 60-month survival rates noted for the head and neck sarcoma cohort reported by Stavrakas et al. [2], of which $23.0 \%$ were sinonasal sarcomas. The sinonasal group in the Stavrakas study [2] had a 60-
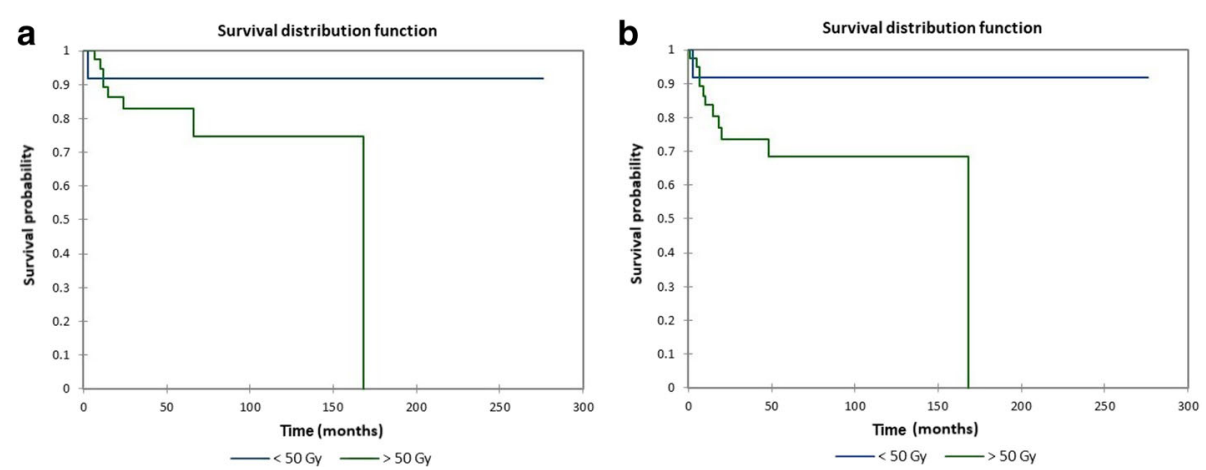

Fig. 7 a Kaplan-Meier overall survival by total radiation dose. b Kaplan-Meier disease-free survival by total radiation dose 



Fig. 8 a Kaplan-Meier overall survival by metastasis (M) stage. b Kaplan-Meier disease-free survival by metastasis (M) stage

month actuarial disease-specific survival of approximately $55 \%$, which is similar to the disease-free survival noted in the present study.

Stephan et al. [3] and Unsal et al. [4] reported outcomes for adult patients with sinonasal rhabdomyosarcoma identified from the National Cancer Database and patients with sinonasal rhabdomyosarcoma identified in the Surveillance, Epidemiology, and End Results (SEER) database, respectively. Stephan et al. [3] noted positive regional nodes in $84.6 \%$ of patients and distant metastasis in $27.7 \%$ of patients, while Unsal et al. [4] noted positive regional nodes in $54.3 \%$ of patients and distant metastasis in $32.2 \%$. The present study noted much lower rates of distant (3.5\%) and neck (3.1\%) metastasis. Stephan et al. [3] and Unsal et. al. [4] also noted lower 60 -month overall survival rates $(28.4 \%$ and $35.1 \%$, respectively) than the present study (61.3\%). In the present study the 60-month survival for the 14 patients with sinonasal rhabdomyosarcoma was $47.2 \%$, which was lower than the actuarial 60-month survival for the entire cohort. The lower survival in the Stephan [3] and Unsal [4] studies is thus likely a combination of a poorer prognosis for sinonasal rhabdomyosarcoma compared to some of the more favorable sarcomas included in the present study such as Ewing's sarcoma and chondrosarcoma, and the higher neck and distant metastasis rate in sinonasal rhabdomyosarcoma vs. the overall cohort in the present study including several less aggressive sarcomas. Stephan et al. [3] noted a significantly lower 60month survival for patients with distant metastasis $(\sim 18 \%)$ vs. M0 patients $(\sim 35 \%)$, similar to the significantly decreased 60-month overall and disease-free survival seen in $\mathrm{M} 1$ patients in the present study (both $0 \%$ at 60 months). Interestingly, Unsal et al. [4] noted significantly lower 60-month survival for patients with distant metastasis but not for patients with regional lymph node metastasis, similar to the findings in the present study.

Combined modality therapy was associated with increased 60-month survival vs. single modality therapy. Sixty-month overall survival rates for surgery + radiation + chemotherapy (90.9\%), surgery + radiation (79.9\%), surgery + chemotherapy (71.3\%), and radiation + chemotherapy $(66.0 \%)$ were significantly higher than surgery $(40.9 \%)$, radiation (NA), and chemotherapy (NA) ( $p$ $<0.0001)$. Sixty-month disease free survival rates for surgery + radiation + chemotherapy $(80.2 \%)$, surgery + radiation (68.8\%), surgery + chemotherapy (57.7\%), and radiation + chemotherapy $(58.4 \%)$ were significantly higher than surgery (39.6\%), radiation (NA), and chemotherapy $(\mathrm{NA})(p<0.0001)$. Stavrakas [2] also noted higher 60-month survival rates for patients treated with
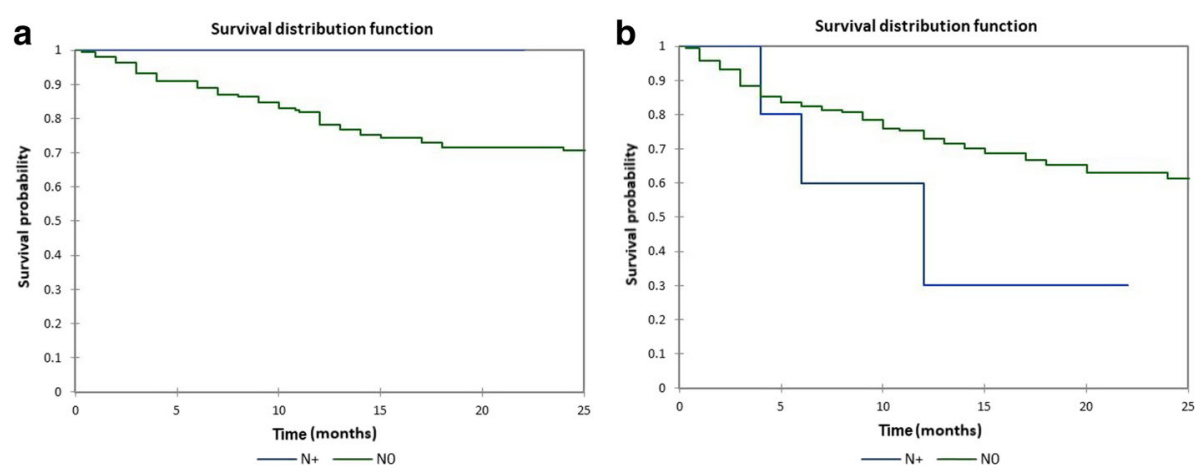

Fig. 9 a. Kaplan-Meier overall survival by neck $(\mathrm{N})$ stage. b Kaplan-Meier disease-free survival by neck $(\mathrm{N})$ stage 

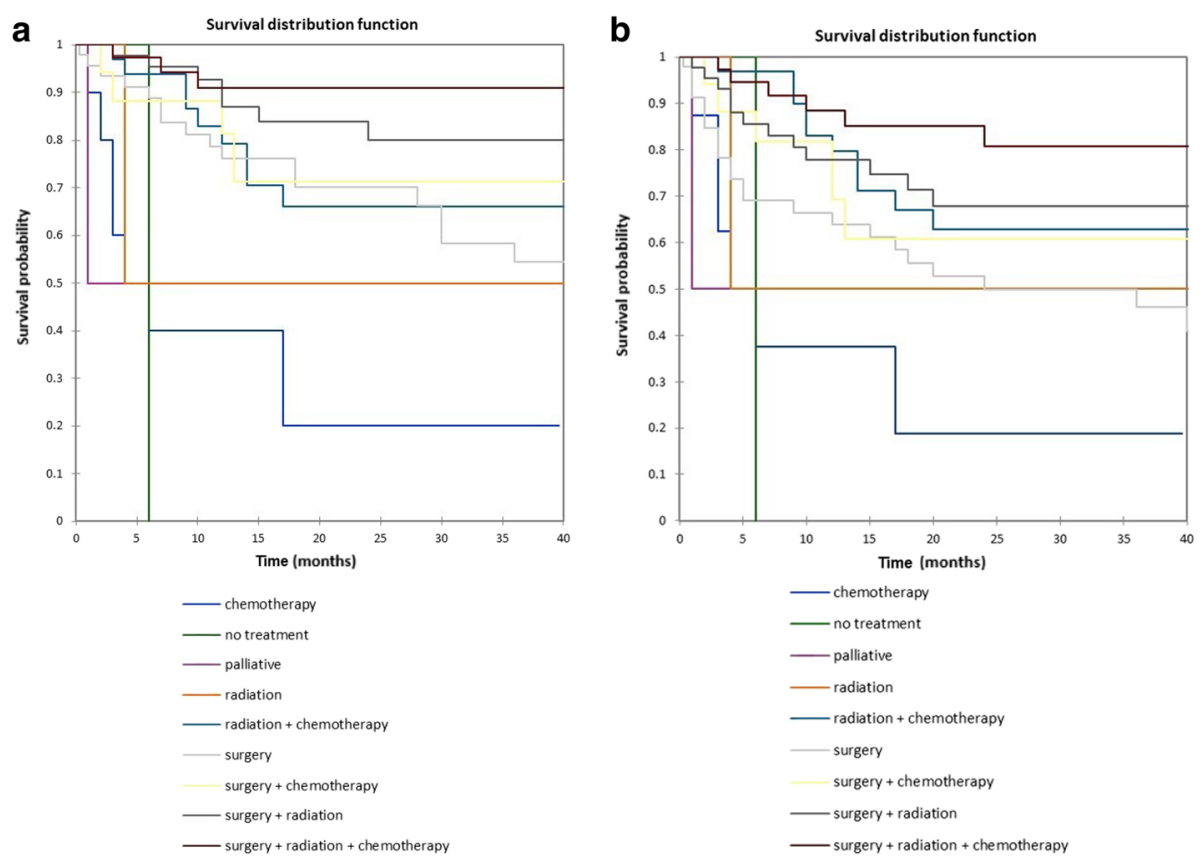

Fig. 10 a Kaplan-Meier overall survival by treatment modality. b Kaplan-Meier disease-free survival by treatment modality

adjuvant therapy vs. surgery alone. In their study of 5 patients with sinonasal Ewing's sarcoma Lombardi et al. [185] noted only one death, due to distant metastases, with all of the 5 patients being treated with multimodality treatment.

Ewing's sarcoma was the most frequent histopathologic type, with 56 patients (28\%), followed by UPS/ MFH with 25 (12.6\%), chondrosarcoma with 16 (8.0\%), and rhabdomyosarcoma $(14,7.0 \%)$, PNET $(14,7.0 \%)$, teratocarcinosarcoma (14, 7.0\%), leiomyosarcoma, (12, $6.0 \%)$, and osteosarcoma (11, 5.6\%). Stavrakas et al. [2] noted sinonasal sarcoma to be the most frequent subsite in their study (23.0\%), with Kaposi sarcoma in $20.5 \%$, chondrosarcoma in $15.3 \%$ of patients and osteosarcoma in $10.2 \%$, and leiomyosarcoma, dermatofibrosarcoma, and spindle cell sarcoma in $7.6 \%$. On univariate analysis
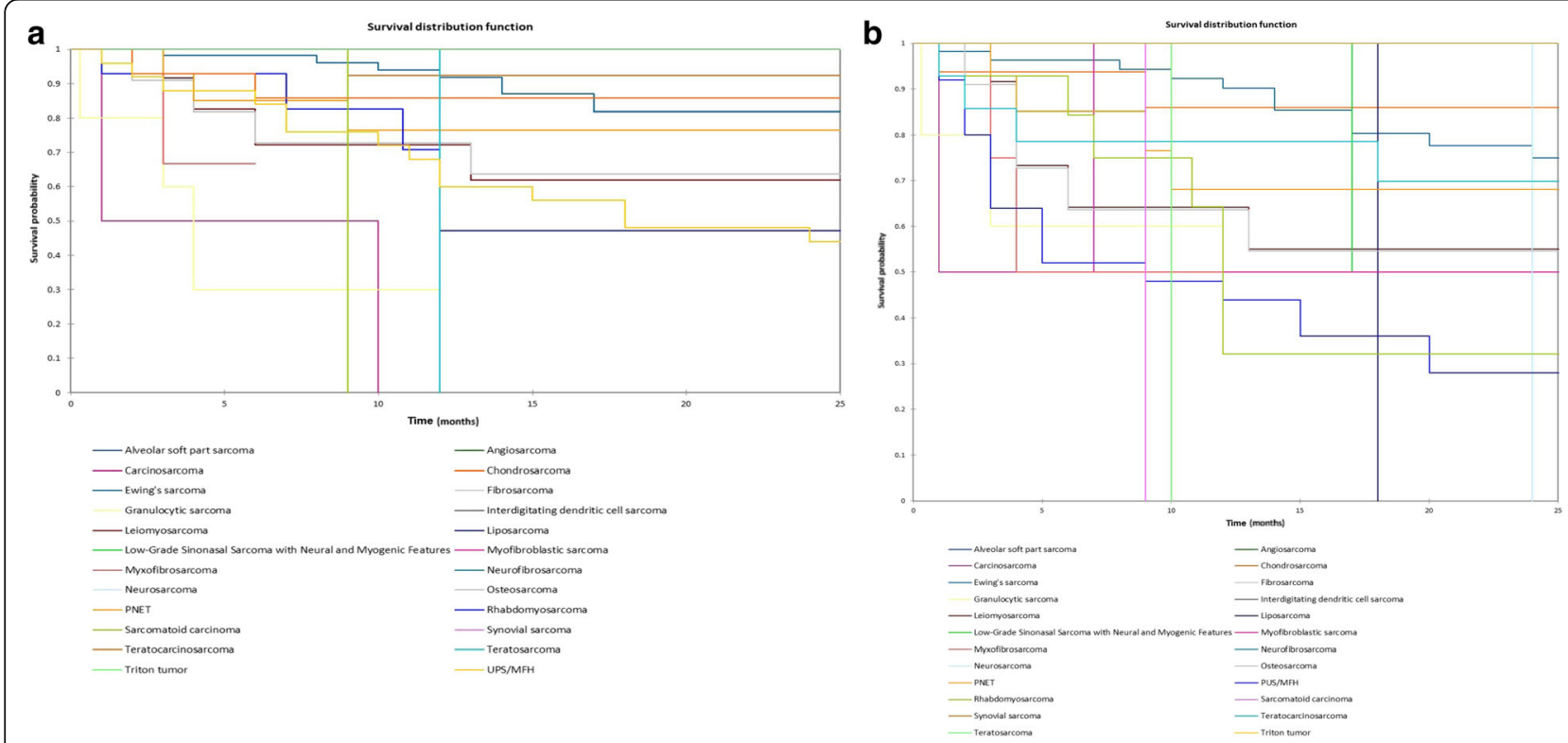

Fig. 11 a Kaplan-Meier overall survival by tumor type. b Kaplan-Meier disease-free survival by tumor type 

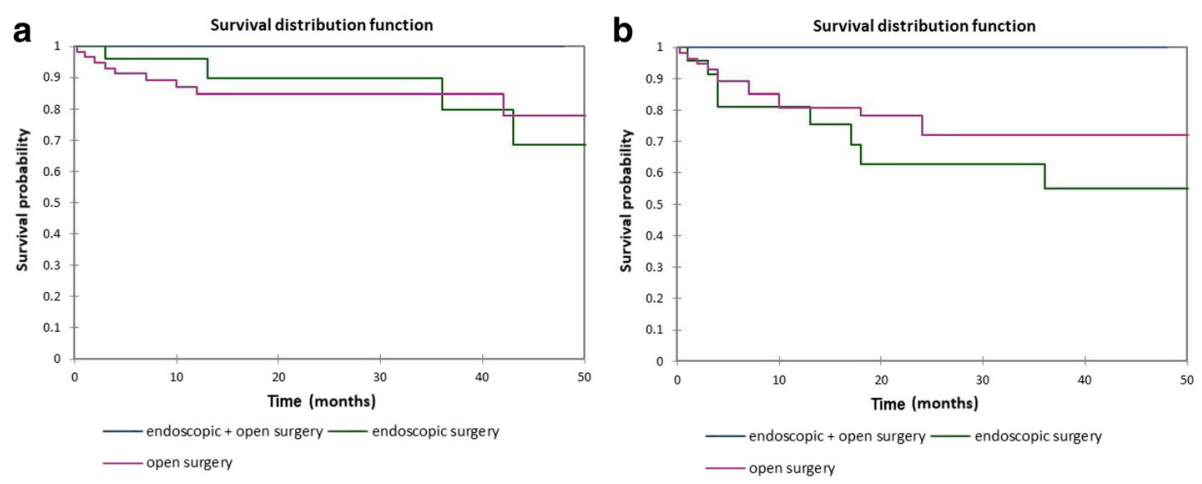

Fig. 12 a Kaplan-Meier overall survival by type of surgery. b Kaplan-Meier disease-free survival by type of surgery

the present study showed a significant association between improved overall and disease-free survival for Ewing's sarcoma, chondrosarcoma, PNET, teratosarcoma, osteosarcoma, leiomyosarcoma, Triton tumor, and myofibroblastic sarcoma vs. UPS/MFH, sarcomatoid sarcoma, rhabdomyosarcoma, neurosarcoma, and carcinosarcoma. The prevalence of Ewing's sarcoma, chondrosarcoma, PNET, teratocarcinosarcoma, osteosarcoma, and leiomyosarcoma in the present study likely contributes to the higher overall and disease-free survival noted in this study vs. the sinonasal rhabdomyosarcoma groups seen in the Stepan [3] and Unsal [4] studies.

Only approximately $3.5 \%$ of patients in the present study had tumor grade information reported. This is lower than the approximately $20.0 \%$ of cases with grade information noted in the Unsal et. al. study [4], but is consistent with a minority of reported cases having specific tumor grade information reported. Unsal et al. [4] proposed that this low number may be due to the heterogeneous pathologic features seen in sarcomas, and the use of histologic subtype as a de facto surrogate for grade (i.e. embryonal vs. alveolar). Despite the low numbers of cases with grade reported in the present study, grade 1 tumors displayed a mean survival ( $\sim 11.0$ months) that was longer than grade 2 (mean 6.0 months) or grade 3 (mean 3.0 months) tumors. This difference approached significance ( $p=0.05$ for OS and $p=0.05$ for DFS). Radiation dose greater or less than 50 Gray and endoscopic vs. endoscopic assisted open vs. open surgery did not have a significant association with survival.

Unsal et al. [4] noted lower 60-month survival for Intergroup Rhabdomyosarcoma Staging Group (IRSG) stage IV patients vs. stage III or II patients, similar to the present study. In the present study overall stage using the AJCC sarcoma staging system was significantly associated with survival, with stage IV patients having significantly lower overall survival than stage III or stage I/II patients. This significant overall survival difference remained significant on multivariate analysis.
The present study has several limitations. The diverse group of histopathological subtypes included in the analysis has the potential to affect the results, adding heterogeneity that would be less prevalent in an analysis of a specific sarcoma subtype. Additionally, the retrospective data introduces the potential for selection and recall bias. Given the relative rarity of sinonasal sarcoma it would be more difficult to assemble randomized controlled trials specific to sinonasal sarcoma that would reduce or eliminate the inherent selection bias. Additionally, the limited available data on tumor grade limits the analysis of tumor grade as a prognostic factor, although even with the low numbers in the present study tumor grade approached significance on univariate analysis.

Overall, the study suggests that combined modality therapy is associated with improved outcomes, and suggests that type of surgery (endoscopic vs. open) does not appear to affect survival. Additionally, the rate of positive cervical nodes at diagnosis was low (3.0\%) in the present study, suggesting that the clinically and radiographically negative neck may not warrant empirical treatment in sinonasal sarcoma. Tumor type and overall stage were significantly associated with survival, making accurate histopathological diagnosis and accurate staging vital. The strengths of this study include the relatively large cohort and the univariate and multivariate survival analysis, and the long follow-up data available on the present cohort, as well as the detailed data collected on tumor types, TNM and overall staging, radiation dose and surgery type. Future prospective studies and/or population-based studies would further add to the data on the effect of treatment type, stage, grade, and tumor histopathology on survival. Additionally, single-tumor-type studies on the more common histopathological subtypes in sinonasal sarcoma may further elucidate treatment and survival characteristics unique to individual subtypes.

\section{Conclusions}

Head and neck sarcoma is a rare entity, comprising $10 \%$ or less of all sarcomas, with sinonasal sarcomas 
likely representing only $25 \%$ or less of head and neck sarcomas. The present study demonstrated a significant association between overall stage and overall survival on univariate and multivariate analysis, and overall stage appeared to be the most significant contributor to survival in the present study. On univariate analysis overall stage, T stage, combined modality vs. single modality therapy, distant metastasis, and tumor subtype all showed a significant correlation with survival. Surgical excision with negative margins when possible combined with adjuvant radiation and/or chemotherapy appears to offer the best survival outcomes. Especially for more favorable tumor subtypes such as Ewing's, PNET, chondrosarcoma, teratocarcinosarcoma, and Triton tumor long-term survival is possible, especially with combined modality therapy.

\section{Additional file}

Additional file 1: PRISMA 2009 checklist for Treatment, Demographics, and Outcomes in Sinonasal Sarcoma: a Systematic Review of the Literature. (DOC 63 kb)

\section{Abbreviations}

AJCC: American Joint Committee on Cancer; DFS: Disease-free survival; G: Grade; M: Metastasis; N: Neck; NA: Not available; OS: Overall survival; PNET: Primitive Neuroectodermal Tumor; PRISMA: Preferred Reporting Items for Systematic Reviews and Meta-Analyses; SEER: Surveillance, Epidemiology, and End Results; T: Tumor; UPS/MFH: Undifferentiated Pleomorphic Sarcoma/ Malignant Fibrous Histiocytoma

\section{Acknowledgements}

None.

\section{Funding}

None.

\section{Availability of data and materials}

Data from the systematic review/meta-analysis can be supplied on request from the corresponding author.

\section{Authors' contributions}

MRG designed the study, performed the literature search, reviewed articles for inclusion and exclusion, performed literature review and meta-analysis, and wrote the manuscript. The author read and approved the final manuscript.

\section{Ethics approval and consent to participate}

Not applicable.

\section{Consent for publication}

Not applicable.

\section{Competing interests}

The author declares that he has no competing interests.

\section{Publisher's Note}

Springer Nature remains neutral with regard to jurisdictional claims in published maps and institutional affiliations.
Received: 21 December 2017 Accepted: 1 March 2018

Published online: 21 March 2018

\section{References}

1. Yamaguchi S, Nagasawa H, Suzuki T, Fujii E, Iwaki H, Takagi M, et al. Sarcomas of the oral and maxillofacial region: a review of 32 cases in 25 years. Clin Oral Investig. 2004;8(2):52-5.

2. Stavrakas M, Nixon I, Andi K, Oakley R, Jeannon JP, Lyons A, et al. Head and neck sarcomas: clinical and histopathological presentation, treatment modalities, and outcomes. J Laryngol Otol. 2016;130(9):850-9.

3. Stepan K, Konuthula N, Khan M, Parasher A, Del Signore A, Govindaraj S, et al. Outcomes in Adult Sinonasal Rhabdomyosarcoma. Otolaryngol Head Neck Surg. 2017:157(1):135-41.

4. Unsal AA, Chung SY, Unsal AB, Baredes S, Eloy JA. A Population-Based Analysis of Survival for Sinonasal Rhabdomyosarcoma. Otolaryngol Head Neck Surg. 2017;157(1):142-9.

5. Gerth DJ, Tashiro J, Thaller SR. Pediatric sinonasal tumors in the United States: incidence and outcomes. J Surg Res. 2014;190(1):214-20.

6. Thompson CF, Kim BJ, Lai C, Grogan T, Elashoff D, St John MA, et al. Sinonasal rhabdomyosarcoma: prognostic factors and treatment outcomes. Int Forum Allergy Rhinol. 2013;3(8):678-83.

7. Thorn AP, Daugaard S, Christensen LH, Christensen IJ, Petersen MM. YKL-40 protein in osteosarcoma tumor tissue. APMIS. 2016;124(6):453-61.

8. Dahodwala MQ, Husain Q, Kanumuri W, Choudhry OJ, Liu JK, Eloy JA. Management of sinonasal hemangiopericytomas: a systematic review. Int Forum Allergy Rhinol. 2013;3(7):581-7.

9. Duval M, Hwang E, Kilty SJ. Systematic review of treatment and prognosis of sinonasal hemangiopericytoma. Head Neck. 2013;35(8):1205-10.

10. Moher D, Liberati A, Tetzlaff J, Altman DG, Group P. Preferred reporting items for systematic reviews and meta-analyses: the PRISMA statement. J Clin Epidemiol. 2009;62(10):1006-12.

11. Sood N, Sehrawat N. Adult onset sinonasal rhabdomyosarcoma - a rare case report with cytohistological features. Malays J Pathol. 2016;38(2):169-73.

12. Gonzalez ME, Raghavan P, Cho B, Muttikkal TJ, Rehm PK. Primary osteogenic osteosarcoma of the ethmoid sinus in an adolescent: case report. J Radiol Case Rep. 2016;10(2):1-9.

13. Mahfoudhi M, Lahiani R. Nasal sinus fibrosarcoma. Pan Afr Med J. 2015:22:172.

14. Zebralla V, Horn IS, Gradistanac T, Dietz A. Space-occupying lesion in the ethmoid sinus area with osseous destruction - benign or malignant? Laryngorhinootologie. 2015;94(11):769-71.

15. Deshmukh SD, Gaurish SK, Pathak N, Rokade V, Jadhav AB. High grade angiosarcoma of nasal cavity and paranasal sinuses: A rare case with immunohistopathological study. Indian J Pathol Microbiol. 2015;58(4):570-2.

16. Zhang C, Wu D, Bi L. Two cases of synovial sarcoma in the head and neck Lin Chung Er Bi Yan Hou Tou Jing Wai Ke Za Zhi. 2015;29(4):375-7.

17. Cannon RB, Wiggins RH 3rd, Witt BL, Dundar Y, Johnston TM, Hunt JP. Imaging and Outcomes for a New Entity: Low-Grade Sinonasal Sarcoma with Neural and Myogenic Features. J Neurol Surg Rep. 2017;78(1):e15-9.

18. Tselis N, Karagiannis E, Kolotas C, Baghi M, Milickovic N, Zamboglou N. Image-guided interstitial high-dose-rate brachytherapy in the treatment of inoperable recurrent head and neck malignancies: An effective option of reirradiation. Head Neck. 2017;39(4):E61-8.

19. Hunsuck EE. Ewing's sarcoma of the maxilla. Report of a case. Oral Surg Oral Med Oral Pathol. 1968;25(6):923-8.

20. Roca AN, Smith JL Jr, Jing BS. Osteosarcoma and parosteal osteogenic sarcoma of the maxilla and mandible: study of 20 cases. Am J Clin Pathol. 1970:54(4):625-36.

21. Thorn D, Mamot C, Krasniqi F, Metternich F, Prestin S. Multimodality Treatment in Ewing's Sarcoma Family Tumors of the Maxilla and Maxillary Sinus: Review of the Literature. Sarcoma. 2016;2016:3872768.

22. Brownson RJ, Cook RP. Ewing's sarcoma of the maxilla. Ann Otol Rhinol Laryngol. 1969;78(6):1299-304.

23. Fernandez CH, Lindberg RD, Sutow WW, Samuels ML. Localized Ewing's sarcoma-treatment and results. Cancer. 1974;34(1):143-8.

24. Ferlito A. Primary Ewing's sarcoma of the maxilla: a clinicopathological study of four cases. J Laryngol Otol. 1978;92(11):1007-24

25. Komray RR. Resident's page. Pathologic quiz case 2. Ewing's sarcoma of the right maxilla. Arch Otolaryngol. 1979;105(2):108-9. 111

26. Strong LC, Herson J, Osborne BM, Sutow WW. Risk of radiation-related subsequent malignant tumors in survivors of Ewing's sarcoma. J Natl Cancer Inst. 1979;62(6):1401-6. 
27. Pontius Kl, Sebek BA. Extraskeletal Ewing's sarcoma arising in the nasal fossa. Light- and electron-microscopic observations. Am J Clin Pathol. 1981;75(3):410-5.

28. Hossfeld DK, Seeber S, Siemers E, Schmidt CG. Chemotherapy of soft tissue sarcomas. Langenbecks Arch Chir. 1981;355:147-51.

29. Slootweg PJ, Straks W, Noorman van der Dussen MF. Primitive neuroectodermal tumour of the maxilla. Light microscopy and ultrastructural observations. J Maxillofac Surg. 1983;11(2):54-7.

30. Bacchini P, Marchetti C, Mancini L, Present D, Bertoni F, Stea G. Ewing's sarcoma of the mandible and maxilla. A report of three cases from the Istituto Beretta. Oral Surg Oral Med Oral Pathol. 1986;61(3):278-83.

31. Siegal GP, Miller EW, Mirmiran SA, Askin FB, Liotta LA. Collagen and laminin immunoreactivity in Ewing's sarcoma: support for an uncommitted mesenchymal cell derivation. Pediatr Pathol. 1986;5(3-4):485-7.

32. Amin MN, Islam KM, Ahmed AN, Datta PG, Amin AS, Abdullah M. Ewing's sarcoma of maxilla-a case report. Bangladesh Med Res Counc Bull. 1990; 16(1):42-5.

33. Filiatrault $D$, Jéquier $S$, Brochu P. Pediatric case of the day. Primitive neuroectodermal tumor (PNET) of the right maxillary sinus. Radiographics. 1993;13(6):1397-9.

34. Jones JE, McGill T. Peripheral primitive neuroectodermal tumors of the head and neck. Arch Otolaryngol Head Neck Surg. 1995;121(12):1392-5.

35. Shah N, Roychoudhury A, Sarkar C. Primitive neuroectodermal tumor of maxilla in an adult. Oral Surg Oral Med Oral Pathol Oral Radiol Endod. 1995; 80(6):683-6.

36. Ibarburen C, Haberman JJ, Zerhouni EA. Peripheral primitive neuroectodermal tumors. CT and MRI evaluation. Eur J Radiol. 1996;21(3):225-32.

37. Fiorillo A, Tranfa F, Canale G, Fariello I, D'Amore R, De Chiara C, et al. Primary Ewing's sarcoma of the maxilla, a rare and curable localization: report of two new cases, successfully treated by radiotherapy and systemic chemotherapy. Cancer Lett. 1996;103(2):177-82.

38. Zheng P, Lu X, Zheng K. Ewing's sarcoma of the maxilla. Chin Med J (Engl). 1998;111(4):377-8

39. A A, El-Husseiny G, Khafaga Y, Kandil A, Gray A, Ezzat A, Schultz H. Ewing's Sarcoma of the Head and Neck: A Retrospective Analysis of 24 Cases. Sarcoma. 1999;3(1):11-5.

40. Toda T, Atari E, Sadi AM, Kiyuna M, Kojya S. Primitive neuroectodermal tumor in sinonasal region. Auris Nasus Larynx. 1999;26(1):83-90.

41. Daw NC, Mahmoud HH, Meyer WH, Jenkins JJ, Kaste SC, Poquette CA, Kun $L E$, Pratt $C B$, Rao BN. Bone sarcomas of the head and neck in children: the St Jude Children's Research Hospital experience. Cancer. 2000;88(9):2172-80.

42. Wexler LH, Meyer WH, Parham DM, Tsokos M. Neural differentiation and prognosis in peripheral primitive neuroectodermal tumor. J Clin Oncol. 2000;18(10):2187-8.

43. Kao SY, Yeung TC, Chou IC, Chang RC. Reconstruction of the severely resorbed atrophic edentulous ridge of the maxilla and mandible for implant rehabilitation: report of a case. J Oral Implantol. 2002;28(3):128-32.

44. Alobid I, Bernal-Sprekelsen M, Alós L, Benítez P, Traserra J, Mullol J. Peripheral primitive neuroectodermal tumour of the left maxillary sinus. Acta Otolaryngol. 2003;123(6):776-8

45. Harman M, Kiroğlu F, Kösem M, Unal O. Primary Ewing's sarcoma of the paranasal sinus with intracranial extension: imaging features. Dentomaxillofac Radiol. 2003;32(5):343-6.

46. Windfuhr JP. Primitive neuroectodermal tumor of the head and neck: incidence, diagnosis, and management. Ann Otol Rhinol Laryngol. 2004; 113(7):533-43.

47. Howarth KL, Khodaei I, Karkanevatos A, Clarke RW. A sinonasal primary Ewing's sarcoma. Int J Pediatr Otorhinolaryngol. 2004;68(2):221-4.

48. Sun Y, Sun BC, Zhao XL, Wang J, Chen J, Li XQ, Feng YM, Fang ZW, Hao XS Roles of immunohistochemistry and detection of SYT-SSX fusion gene in diagnosis of synovial sarcoma. Zhonghua Bing Li Xue Za Zhi. 2007;36(7):480-4.

49. Infante-Cossio P, Gutierrez-Perez JL, Garcia-Perla A, Noguer-Mediavilla M, Gavilan-Carrasco F. Primary Ewing's sarcoma of the maxilla and zygoma: report of a case. J Oral Maxillofac Surg. 2005;63(10):1539-42.

50. Coskun BU, Cinar U, Savk H, Basak T, Dadas B. Isolated maxillary sinus Ewing's sarcoma. Rhinology. 2005;43(3):225-8.

51. Varshney S, Bist SS, Gupta N, Bhatia R. Primary extraskeletal Ewing's sarcoma of the maxilla with intraorbital extension. Indian J Otolaryngol Head Neck Surg. 2007;59(3):273-6.

52. Thariat J, Italiano A, Peyrade F, Birtwisle-Peyrottes I, Gastaud L, Dassonville O, et al. Very Late Local Relapse of Ewing's Sarcoma of the Head and Neck treated with Aggressive Multimodal Therapy. Sarcoma. 2008;2008:854141.
53. Prasad KC, Alva TB, Khadilkar U, Madhu D. Leiomyosarcoma of the maxillary sinuses: report of two cases. Ear Nose Throat J. 2004;83(2):122. 124, 126-7

54. Prasad K, Dexith J, Lalitha RM, Ranganath K, Shuba R, Kumari MK, Mysorekar $\checkmark$. Maxillary osteosarcoma masquerading as chondromyxoid fibroma: report of a case. J Maxillofac Oral Surg. 2015;14(Suppl 1):87-92.

55. Mohindra S, Savardekar A, Mahalingam SS, Mohindra S, Vashista RK. Primary osteosarcoma of clivus: a short report. Br J Neurosurg. 2014;28(4):531-3.

56. Bornstein MM, von Arx T, Altermatt HJ. Loss of pulp sensitivity and pain as the first symptoms of a Ewing's sarcoma in the right maxillary sinus and alveolar process: report of a case. J Endod. 2008;34(12):1549-53.

57. Kawabata M, Yoshifuku K, Sagara Y, Kurono Y. Ewing's sarcoma/primitive neuroectodermal tumour occurring in the maxillary sinus. Rhinology. 2008; 46(1):75-8.

58. Ataergin S, Ozet A, Solchaga L, Turan M, Beyzadeoglu M, Oysul K, et al. Long-lasting multiagent chemotherapy in adult high-risk Ewing's sarcoma of bone. Med Oncol. 2009;26(3):276-86.

59. Piloni MJ, Molina G, Keszler A. Malignant oral-maxillary neoplasm in children and adolescents. A retrospective analysis from the biopsy service at a school of dentistry in Argentina. Acta Odontol Latinoam. 2009:22(3):233-8.

60. Gupta S, Gupta OP, Mehrotra S, Mehrotra D. Ewing sarcoma of the maxilla: a rare presentation. Quintessence Int. 2009:40(2):135-40.

61. Hormozi AK, Ghazisaidi MR, Hosseini SN. Unusual presentation of peripheral primitive neuroectodermal tumor of the maxilla. J Craniofac Surg. 2010; 21(6):1761-3.

62. N D, Rigolet A, Kerner S, Gruffaz F, Boucher Y. Case of Ewing's sarcoma misdiagnosed as a periapical lesion of maxillary incisor. J Endod. 2011;37(2): 259-64.

63. Hafezi S, Seethala RR, Stelow EB, Mills SE, Leong IT, MacDuff E, et al. Ewing's family of tumors of the sinonasal tract and maxillary bone. Head Neck Pathol. 2011:5(1):8-16.

64. Yeshvanth SK, Ninan K, Bhandary SK, Lakshinarayana KP, Shetty JK, Makannavar JH. Rare case of extraskeletal Ewings sarcoma of the sinonasal tract. J Cancer Res Ther. 2012;8(1):142-4.

65. Dutta M, Ghatak S, Biswas G, Sen A. Primary soft tissue Ewing's sarcoma of the maxillary sinus in elderly patients: presentation, management and prognosis. Singapore Med J. 2014;55(6):e96-100.

66. Grevener K, Haveman LM, Ranft A, van den Berg H, Jung S, Ladenstein R, et al. Management and Outcome of Ewing Sarcoma of the Head and Neck. Pediatr Blood Cancer. 2016;63(4):604-10.

67. Spalthoff S, Bredt M, Gellrich NC, Jehn P. A Rare Pathology: Low-Grade Fibromyxoid Sarcoma of the Maxilla. J Oral Maxillofac Surg. 2016;74(1):219.e1-10.

68. Shin M, Kondo K, Hanakita S, Suzukawa K, Kin T, Shojima M, et al. Endoscopic transnasal approach for resection of locally aggressive tumors in the orbit. J Neurosurg. 2015;123(3):748-59.

69. Sugawara T, Aoyagi M, Ogishima T, Kawano Y, Tamaki M, Yano T, et al. Extended orbital exenteration for sinonasal malignancy with orbital apex extension: surgical technique and clinical analysis. J Neurosurg. 2015;123(1):52-8.

70. Ando M, Saito Y, Morikawa T, Omura G, Kobayashi K, Akashi K, et al. Maxillary carcinosarcoma: Identification of a novel MET mutation in both carcinomatous and sarcomatous components through next generation sequencing. Head Neck. 2015:37(12):E179-85.

71. Chen S, Mattei P, Berli JU, Shores J. Myxofibrosarcoma with associated Mycobacterium infection. Eplasty. 2014;14:ic18.

72. Es-Sbissi F, Nitassi S, Boulaadas M, Essakalli L. Sinonasal angiosarcoma. Eur Ann Otorhinolaryngol Head Neck Dis. 2015:132(3):161-3.

73. Ila K, Işeri M, Erdoğan S, Keskin G, Koç K, Müezzinoğlu B. Sinonasal teratocarcinosarcoma. Kulak Burun Bogaz Ihtis Derg. 2014;24(4):237-41.

74. Cheong JP, Rahayu S, Halim A, Khir A, Noorafidah D. Report of a rare case of carcinosarcoma of the maxillary sinus with sternal metastasis. Ear Nose Throat J. 2014;93(6):E1-4.

75. Cruz S, Azevedo P, Trigueiros N, Rodrigues e Rodrigues M. Ewing's sarcoma: A rarity in sinonasal region. Acta Otorrinolaringol Esp. 2015;66(3):171-4.

76. Yang F, Zhao Y, Huang S, Sun R, Lei L. Four cases of extraskeletal Ewing's sarcoma in the head and neck and literature review. Lin Chung Er Bi Yan Hou Tou Jing Wai Ke Za Zhi. 2013;27(18):1000-2. 1005

77. Taghipour, Zahir S, Sharahjin NS. Leiomyosarcoma of the maxilla in a 24year-old man who initially presented with odontalgia, and suffered from tumour mismanagement. BMJ Case Rep. 2013;2013:1-4.

78. Shukla D, Rao VS, Rajesh A, Purohit AK. Neglected primary Ewing's sarcoma of ethmoid presenting as surgical emergency. Asian J Neurosurg. 2013;8(1):51-3. 
79. Lee EJ, Hyun DW, Cho HJ, Lee JG. A rare case of interdigitating dendritic cell sarcoma in the nasal cavity. Case Rep Otolaryngol. 2013;2013:913157.

80. Yamaoka M, Akiyama M, Yokokawa Y, Terao Y, Yokoi K, Kato T, Fukushima T, Sakurai $\mathrm{H}$, Ida H. Multidisciplinary therapy including proton beam radiotherapy for a Ewing sarcoma family tumor of maxillary sinus in a 4 year-old girl. Head Neck. 2013;35(12):E386-90.

81. Thakar S, Dadlani R, Furtado SV, Ghosal N, Hegde AS. Extensive anterior skull-base mesenchymal chondrosarcoma: unusual cause of multiple indolent masses on the forehead. Clin Neuropathol. 2013;32(5):393-8.

82. Wassef SN, Kapur P, Barnett SL, Myers LL. Sinonasal teratocarcinosarcoma with intracranial extension: case report and literature review. Ear Nose Throat J. 2012;91(12):536-9.

83. Jiang X, Huang Q, Tang J, Hoffman MR. Monophasic epithelial synovial sarcoma accompanied by an inverted papilloma in the sphenoid sinus. Case Rep Med. 2012;2012:379720.

84. Peregud-Pogorzelski J, Wawrykow P, Wozniak S, Zakowska A, Brodkiewicz A. Highly effective unconventional management of aspergillosis of the left maxillary sinus in an 11-year-old girl with rhabdomyosarcoma embryonale of the frontal sinus. J Med Microbiol. 2013;62(Pt 4):652-4.

85. Kiratli H, Dikmetaş O, Tarlan B, Onerci M. Orbital chondrosarcoma arising from paranasal sinuses. Int Ophthalmol. 2013:33(4):403-7.

86. d'Adesky C, Duterme JP, Lejeune D, Mehta R, Chaikh A, Castadot P, Duchateau JP. Leiomyosarcoma of the inferior nasal concha: a case report and literature review. B-ENT. 2012;8(3):213-7.

87. El Sanharawi A, Coulibaly B, Bessede JP, Aubry K. Paranasal sinus rhabdomyosarcoma: a rare tumor of poor prognosis. Eur Ann Otorhinolaryngol Head Neck Dis. 2013;130(1):26-9.

88. Subramaniam MM, Shuen CS, Petersson F. Poorly differentiated synovial sarcoma of the sphenoid sinus: report of the first case and review of synovial sarcomas of the sinonasal tract. Histopathology. 2012;61(6):1232-7.

89. Agrawal N, Chintagumpala M, Hicks J, Eldin K, Paulino AC. Sinonasal teratocarcinosarcoma in an adolescent male. J Pediatr Hematol Oncol. 2012; 34(7):e304-7.

90. Taghi AS, Ali A, Kuchai R, Saleh H. Rare sarcoma presented as sinusitis. BMJ Case Rep. 2012;2012:1-4.

91. Yamada SM, Ishii Y, Yamada S, Kuribayashi S, Kumita S, Matsuno A. Advanced therapeutic strategy for radiation-induced osteosarcoma in the skull base: a case report and review. Radiat Oncol. 2012;7:136.

92. Aditya A, Lele S. A nodular growth on maxillary gingiva. Indian J Dent Res. 2012;23(1):116-9.

93. Wahid Fl, Javaid M, Khan Q, Khan IA. Sinonasal teratocarcinosarcoma. J Coll Physicians Surg Pak. 2012;22(5):335-7.

94. Peng G, Ke Y, Wang T, Feng Y, Li Y, Wu G. Intensity-modulated radiotherapy for sinonasal teratocarcinosarcoma. J Huazhong Univ Sci Technolog Med Sci. 2011;31(6):857-60.

95. Kim JH, Maeng YH, Lee JS, Jung S, Lim SC, Lee MC. Sinonasal teratocarcinosarcoma with rhabdoid features. Pathol Int. 2011;61(12):762-7.

96. Bercin S, Muderris T, Kırıs M, Kanmaz A, Kandemir OA. rare sinonasal neoplasm: fibrosarcoma. Ear Nose Throat J. 2011:90(5):E6-8.

97. Franchi A, Palomba A, Cardesa A. Current diagnostic strategies for undifferentiated tumours of the nasal cavities and paranasal sinuses. Histopathology. 2011;59(6):1034-45.

98. Chen SC, Bee YS, Lin MC, Sheu SJ. Extensive alveolar-type paranasal sinus and orbit rhabdomyosarcoma with intracranial invasion treated successfully. J Chin Med Assoc. 2011;74(3):140-3.

99. Ben Hassine L, Chaouch S, Douira W, Louati H, Lahmar L, Fdhila F, et al. Granulocytic sarcoma of the maxillary sinus: a pediatric case report. Tunis Med. 2011;89(3):305-8

100. Terada T. Pure sarcomatoid carcinoma of maxillary sinus and nasal cavity simulating malignant fibrous histiocytoma. Am J Clin Pathol. 2011;135(1):128-31.

101. Alameda YA, Perez-Mitchell C, Busquets JM. Nasal cavity ossifying fibrosarcoma: an unusual fibro-osseous neoplasm. Ear Nose Throat J. 2010;89(11):E1-3.

102. Fitzpatrick SG, Woodworth BA, Monteiro C, Makary R. Nasal sinus leiomyosarcoma in a patient with history of non-hereditary unilateral treated retinoblastoma. Head Neck Pathol. 2011;5(1):57-62.

103. Acosta Díaz H, Trinidad Ruiz G, Rejas E, Pando J, Cabrera JJ. Synovial sarcoma of the nasal cavity. A case report. Acta Otorrinolaringol Esp. 2011; 62(3):246-8.

104. Kharrat S, Sahtout S, Tababi S, Temimi S, Ben Miled M, Abid W, et al. Chondrosarcoma of sinonasal cavity: a case report and brief literature review. Tunis Med. 2010;88(2):122-4.
105. Chew YK, Noorizan Y, Khir A, Brito-Mutunayagam S. Leiomyosarcoma of the maxillary sinus. Med J Malaysia. 2009;64(2):174-5.

106. Su YY, Friedman M, Huang CC, Wilson M, Lin HC. Sinonasal teratocarcinosarcoma. Am J Otolaryngol. 2010;31(4):300-3.

107. Thompson SM, Duque CS, Sheth RN, Casiano RR, Morcos JJ, GomezFernandez CR. Case report: Liposarcoma of the sinonasal tract. Br J Radiol. 2009;82(980):e160-3.

108. Rahal A, Durio JR, Hinni ML. Chondrosarcoma of the nasal septum. Ear Nose Throat J. 2009;88(1):744-5.

109. Legendre BW, Nelson BL. Alveolar rhabdomyosarcoma of the paranasal sinuses. Head Neck Pathol. 2008;2(4):302-4.

110. Wei S, Carroll W, Lazenby A, Bell W, Lopez R, Said-Al-Naief N. Sinonasal teratocarcinosarcoma: report of a case with review of literature and treatment outcome. Ann Diagn Pathol. 2008;12(6):415-25.

111. Wang $C P$, Chang $Y L$, Ting LL, Yang $T L$, Ko JY, Lou PJ. Malignant fibrous histiocytoma of the sinonasal tract. Head Neck. 2009;31(1):85-93.

112. Hosokawa S, Takebayashi S, Mineta H, Suzuki K, Baba S. Undifferentiated sarcoma of the maxillary sinus: report of a rare case in an adult. Auris Nasus Larynx. 2009;36(1):92-5.

113. Di Tommaso L, Colombo G, Miceli S, Ferrari B, Santoro A, Poletti A, et al. Angiosarcoma of the nasal cavity. Report of a case and review of the literature. Pathologica. 2007;99(3):76-80.

114. Kim YJ, Im SA, Lim GY, Chun HJ, Park HJ, Kim MS, et al. Myxoid chondrosarcoma of the sinonasal cavity in a child: a case report. Korean J Radiol. 2007:8(5):452-5.

115. Zhang $X$, Yang C, Kong W, Jiang H, Zhang L, Li M. Osteogenic sarcoma in frontal sinus: one case with literature review. Lin Chuang Er Bi Yan Hou Ke Za Zhi. 2006;20(24):1130-1.

116. Khademi B, Owji SM, Khosh KJ, Mohammadianpanah M, Gandomi B. Description of a neural sheath tumor of the trigeminal nerve: immunohistochemical and electron microscopy study. Sao Paulo Med J. 2006:124(6):333-5

117. Adenis T, Labrousse F, Sauvage JP, Robert PY. Granulocytic sarcoma in a 90year-old patient. J Fr Ophtalmol. 2006;29(8):961-4.

118. Taori K, Chandanshive S, Attarde V, Patil P, Rangankar V, Londhe S. Nasal chondrosarcoma in an infant: radiologic and histologic correlation. AJNR Am J Neuroradiol. 2006;27(7):1394-5.

119. Moon HS, Kwon SW, Lee JH. A case of alveolar rhabdomyosarcoma of the ethmoid sinus invading the orbit in an adult. Korean J Ophthalmol. 2006; 20(1):70-5.

120. Takasaki K, Sakihama N, Takahashi H. A case with sinonasal teratocarcinosarcoma in the nasal cavity and ethmoid sinus. Eur Arch Otorhinolaryngol. 2006;263(6):586-91.

121. Betz CS, Janda P, Arbogast S, Leunig A. Myxoma and myxoid chondrosarcoma of the nasal septum: two case reports. HNO. 2007;55(1):51-5.

122. Plaza G, Ferrando J, Pinedo F. Sinonasal fibrosarcoma: a case report. Eur Arch Otorhinolaryngol. 2006;263(7):641-3.

123. Ferri E, Minotto C, lanniello F, Cavaleri S, Armato E, Capuzzo P. Maxilloethmoidal chloroma in acute myeloid leukaemia: case report. Acta Otorhinolaryngol Ital. 2005;25(3):195-9.

124. Muto E, Shioyama Y, Nakamura K, Ohga' S, Nomoto S, Toba T, Yoshitake T, Soeda $\mathrm{H}$, Terashima $\mathrm{H}$, Honda $\mathrm{H}$, et al. Adult rhabdomyosarcoma in the nasal and paranasal sinuses showing complete local response to a combination of chemotherapy and radiotherapy using 3D-CRT and IMRT. Fukuoka Igaku Zasshi. 2005:96(10):363-9.

125. Nitsche M, Hermann RM, Christiansen H, Berger J, Pradier O. Rationale for individualized therapy in Sinonasal Teratocarcinosarcoma (SNTC): case report. Onkologie. 2005;28(12):653-6.

126. Kohanawa R, Tabuchi K, Okubo H, Nagata M, Hara A. Primary osteogenic sarcoma of the ethmoid sinus: a case report. Auris Nasus Larynx. 2005;32(4):411-3.

127. Namysłowski G, Scierski W, Turecka L, Urbaniec N, Lange DA. very rare case of low-grade angiosarcoma of the nose and paranasal sinuses. Otolaryngol Pol. 2005;59(1):105-8.

128. Tseng CC, Lin CZ, Li WY. Pathology quiz case 2. Postirradiation sinonasal osteosarcoma. Arch Otolaryngol Head Neck Surg. 2005;131(2):173. 175-6

129. Yigitbasi OG, Guney E, Kontas O, Somdas MA, Patiroglu T. Alveolar soft part sarcoma: report of a case occurring in the sinonasal region. Int J Pediatr Otorhinolaryngol. 2004:68(10):1333-7.

130. Osuch-Wójcikiewicz E, Korolkowa O, Nyckowska J, Bruzgielewicz A. Rhabdomyosarcoma of the nasopharynx-a case report. Otolaryngol Pol. 2004;58(3):631-4. 
131. Carrau RL, Aydogan B, Hunt JL. Chondrosarcoma of the sphenoid sinus resected by an endoscopic approach. Am J Otolaryngol. 2004;25(4):274-7.

132. Park HR, Min SK, Cho HD, Cho SJ, Lee JH, Lee $Y$, et al. Osteosarcoma of the ethmoid sinus. Skeletal Radiol. 2004;33(5):291-4.

133. Sandruck J, Escobar P, Lurain J, Fishman D. Uterine leiomyosarcoma metastatic to the sphenoid sinus: a case report and review of the literature. Gynecol Oncol. 2004;92(2):701-4.

134. Chao KK, Eng TY, Barnes J, Dahiya R. Sinonasal teratocarcinosarcoma. Am J Clin Oncol. 2004;27(1):29-32.

135. Kuhn FA, Javer AR. Low-grade fibrosarcoma of the anterior skull base: endoscopic resection and repair. Am J Rhinol. 2003;17(6):347-50.

136. Donaldson ME, Geist JR, Daley TD. Osteosarcoma of the jaws in children. Int J Paediatr Dent. 2004;14(1):54-60

137. Aferzon M, Wood WE, Powell JR. Ewing's sarcoma of the ethmoid sinus. Otolaryngol Head Neck Surg. 2003;128(6):897-901.

138. Krömer JH, Ludwig K, Bürger H, Alberty J. Chondrosarcoma of the sphenoethmoid complex: Case report. Laryngorhinootologie. 2002;81(10):702-5

139. Re M, Romeo R, Mallardi V. Paralateral-nasal malignant schwannoma with rhabdomyoblastic differentiation (Triton tumor). Report of a case. Acta Otorhinolaryngol Ital. 2002;22(4):245-7.

140. Wellman M, Kerr PD, Battistuzzi S, Cristante L. Paranasal sinus teratocarcinosarcoma with intradural extension. J Otolanyngol. 2002;31(3):173-6.

141. Chen CC, Hsu L, Hecht IL, Janecka I. Bimaxillary chondrosarcoma: clinical radiologic, and histologic correlation. AJNR Am J Neuroradiol. 2002;23(4):667-70.

142. Ortega JM, Gómez-Angulo JC, Aragonés P, Jerez P, Alcázar L, RodríguezBarbero JM, Salazar F, del Pozo JM. Leiomyosarcoma of the paranasal sinuses with intracranial involvement: report of a clinical case and review of the literature. Neurocirugia (Astur). 2001;12(4):331-7.

143. Furuta $Y$, Nojima T, Terakura N, Fukuda S, Inuyama $Y$. A rare case of carcinosarcoma of the maxillary sinus with osteosarcomatous differentiation. Auris Nasus Larynx. 2001;28(Suppl):S127-9.

144. Galera-Ruiz H, Sanchez-Calzado JA, Rios-Martin JJ, DeMingo-Fernandez EJ, Muñoz Borge F. Sinonasal radiation-associated osteosarcoma after combined therapy for rhabdomyosarcoma of the nose. Auris Nasus Larynx. 2001;28(3):261-4.

145. Keck T, Mattfeldt T, Kühnemann S. Leiomyosarcoma of the ethmoidal cells. Rhinology. 2001;39(2):115-7.

146. Arita K, Sugiyama K, Tominaga A, Yamasaki F. Intrasellar rhabdomyosarcoma: case report. Neurosurgery. 2001;48(3):677-80

147. Uysal KM, Koyuncuoğlu M, Akman F, Güneri A, Sarialioğlu F, Kargi A, et al. A rare tumor of craniofacial bones in children: a pediatric chondroblastic osteosarcoma case with diagnostic and therapeutic problems. Pediatr Hematol Oncol. 2001;18(2):147-52.

148. Esmaeli B, Medeiros LJ, Myers J, Champlin R, Singh S, Ginsberg L. Orbital mass secondary to precursor T-cell acute lymphoblastic leukemia: a rare presentation. Arch Ophthalmol. 2001;119(3):443-6.

149. Osuch-Wójcikiewicz E, Balcerzak J, Bruzgielewicz A, Checiński P. A case of maxillary neurosarcoma. Otolaryngol Pol. 2000;54(5):583-6.

150. Klippenstein KA, Wesley RE, Glick AD. Orbital leiomyosarcoma after retinoblastoma. Ophthalmic Surg Lasers. 1999;30(7):579-83.

151. Velegrakis GA, Panayiotides JG, Skoulakis CE, Papadakis CE, Papadakis DG, Bizakis JG, et al. Angiosarcoma of the maxillary sinus. J Laryngol Otol. 2000; 114(5):381-4.

152. Shimazaki H, Aida S, Tamai S, Miyazawa T, Nakanobou M. Sinonasal teratocarcinosarcoma: ultrastructural and immunohistochemical evidence of neuroectodermal origin. Ultrastruct Pathol. 2000;24(2):115-22.

153. Ogawa T, Ikeda K, Watanabe M, Satake M, Oshima T, Suzuki N, Nakano H, Matsuura K, Sato M, Takasaka T. A case report of sinonasal teratocarcinosarcoma. Tohoku J Exp Med. 2000;190(1):51-9.

154. Kachhara R, Nair S, Sandhyamani S, Bhattacharya RN. Primary osteogenic sarcoma involving sella-sphenoid sinus-case report. Neurol Med Chir (Tokyo). 1999;39(7):534-8.

155. Lam DS, Li CK, Cheng LL, Teo JG, Chik KW, Kwan WH, et al. Primary orbital Ewing's sarcoma: report of a case and review of the literature. Eye (Lond). 1999:13(Pt 1):38-42.

156. Jund R, Leunig A, Hagedorn H, Nerlich A, Grevers G. Embryonal rhabdomyosarcoma of the nose in an elderly patient, case report and review of the literature. Auris Nasus Larynx. 1998;25(4):445-50.

157. Takamura H, Yamaguchi K, Takahashi S, Aoyagi MA. case of orbital mesenchymal chondrosarcoma. Nippon Ganka Gakkai Zasshi. 1998;102(10):692-7.
158. Terasaka S, Medary MB, Whiting DM, Fukushima T, Espejo EJ, Nathan G. Prolonged survival in a patient with sinonasal teratocarcinosarcoma with cranial extension. Case report. J Neurosurg. 1998;88(4):753-6.

159. Epley KD, Lasky JB, Karesh JW. Osteosarcoma of the orbit associated with Paget disease. Ophthal Plast Reconstr Surg. 1998;14(1):62-6.

160. Rapidis AD, Archondakis G, Anteriotis D, Skouteris CA. Chondrosarcomas of the skull base: review of the literature and report of two cases. J Craniomaxillofac Surg. 1997;25(6):322-7.

161. Ikeda K, Kudo T, Shimomura A, Oshima T, Suzuki N, Kakehata S, et al. A case of leiomyosarcoma of the sphenoid sinus. Tohoku J Exp Med. 1997;182(3):265-70

162. Chynn EW, Rubin PA. Metastatic Ewing cell sarcoma of the sinus and osteoid osteoma of the orbit. Am J Ophthalmol. 1997;123(4):565-7.

163. Sugiyama K, Hirano A, Llena JF, Goodrich JT, Uozumi T, Kurisu K, et al. Mesenchymal chondrosarcoma in anterior skull base: case report. Noshuyo Byori. 1996;13(1):57-60

164. Lippert BM, Godbersen GS, Lüttges J, Werner JA. Leiomyosarcoma of the nasal cavity. Case report and literature review. ORL J Otorhinolaryngol Relat Spec. 1996;58(2):115-20.

165. Koenigsberg RA, Noah R, Turtz A, Goldman W, Holland RS, Nicosia RF, et al. Rhabdomyosarcoma of the paranasal sinuses in an adult. Clin Imaging. 1995;19(4):234-6.

166. Reich DS, Palmer CA, Peters GE. Ethmoid sinus leiomyosarcoma after cyclophosphamide treatment. Otolaryngol Head Neck Surg. 1995;113(4):495-8.

167. Lauer SA, Friedland S, Goodrich JT, Dorfman H. Mesenchymal chondrosarcoma with secondary orbital invasion. Ophthal Plast Reconstr Surg. 1995;11(3):182-6.

168. Shemen L, Galantich P, Murali R. Malignant teratocarcinosarcoma of the sphenoid sinus. Otolaryngol Head Neck Surg. 1995;112(3):496-500.

169. Namysłowski G, Czecior E, Ponińska-Polańczuk J, Anczykowska M. Chondrosarcoma of the paranasal sinuses and orbit. Otolaryngol Pol. 1995;49(1):64-7.

170. Nakane T, Hashizume Y, Tachibana E, Mizutani N, Handa T, Mutsuga N, et al. Primary Ewing's sarcoma of the skull base with intracerebral extension-case report. Neurol Med Chir (Tokyo). 1994:34(9):628-30.

171. Kumar L, Kochupillai V, Bhargava M. Granulocytic sarcoma of the paranasa sinus. J Assoc Physicians India. 1992:40(1):51-2.

172. Redondo Martínez E, Rey López A, Reguera Parra V, Bolaños Rodríguez C. Sinusal teratocarcinosarcoma. Acta Otorrinolaringol Esp. 1991:42(5):363-7.

173. Yamaki T, Uede T, Tano-oka A, Asakura K, Tanabe S, Hashi K. Vascularized omentum graft for the reconstruction of the skull base after removal of a nasoethmoidal tumor with intracranial extension: case report. Neurosurgery. 1991;28(6):877-80

174. Nakhleh RE, Swanson PE, Dehner LP. Juvenile (embryonal and alveolar) rhabdomyosarcoma of the head and neck in adults. A clinical, pathologic, and immunohistochemical study of 12 cases. Cancer. 1991;67(4):1019-24.

175. Gupta D, Vishwakarma SK. Osteogenic sarcoma of the frontal sinus. Ann Otol Rhinol Laryngol. 1990:99(6 Pt 1):489-90.

176. Wang RH. Primary cyst and tumor in the sphenoid sinus. Zhonghua Zhong Liu Za Zhi. 1990;12(2):130-1.

177. Meyer C, Hauck KW, Gonzalez C. Chondrosarcoma of the facial skeleton in a child. Otolaryngol Head Neck Surg. 1989;101(5):591-4.

178. Sonobe H, Hayashi K, Takahashi K, Ohtsuki Y, Kishimoto S, Saito H, et al. True carcinosarcoma of the maxillary sinus. Pathol Res Pract. 1989;185(4):488-92. discussion 493-5

179. Kurien M, Nair S, Thomas S. Angiosarcoma of the nasal cavity and maxillary antrum. J Laryngol Otol. 1989:103(9):874-6.

180. Shajrawi I, Podoshin L, Fradis M, Boss JH. Malignant triton tumor of the nose and paranasal sinuses: a case study. Hum Pathol. 1989;20(8):811-4.

181. Smith MC, Soames JV. Fibrosarcoma of the ethmoid. J Laryngol Otol. 1989; 103(7):686-9.

182. Bradley C, McClymont LG, Reid R. Osteogenic sarcoma of the ethmoid sinus. J Laryngol Otol. 1988:102(12):1176-8.

183. Bates GJ, Herdman RC. Chondrosarcoma of the sphenoid-a case report and review. J Laryngol Otol. 1988;102(8):727-9.

184. Leung AK. Rhabdomyosarcoma simulating dental abscess. Oral Surg Oral Med Oral Pathol. 1988;65(1):114.

185. Lombardi D, Mattavelli D, Redaelli De Zinis LO, Accorona R, Morassi ML, Facchetti F, et al. Primary Ewing's sarcoma of the sinonasal tract in adults: A challenging disease. Head Neck. 2017:39(3):E45-50. 